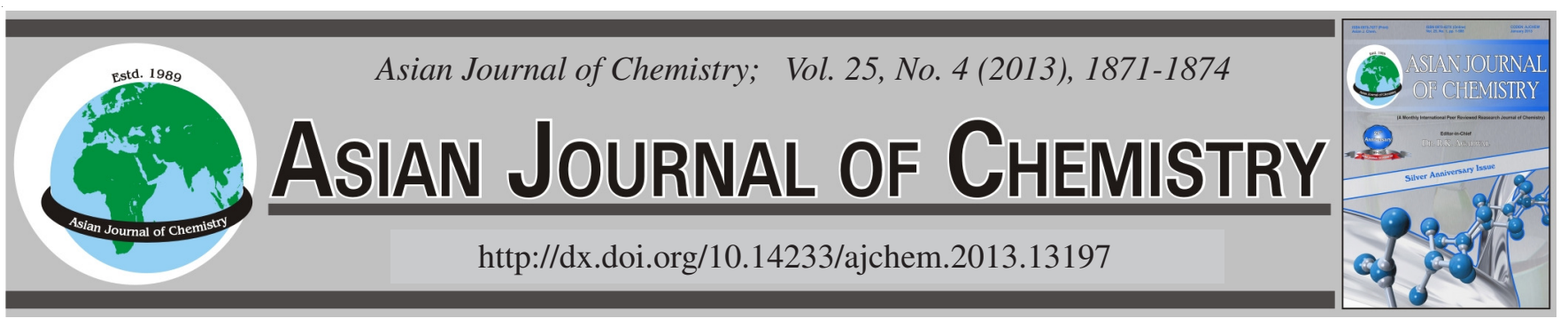

\title{
Corrosion Inhibition Mechanism of Benzimidazole and Its Derivatives on Mild Steel: Quantitative Structure and Property Relationship Study
}

\author{
GuangZeng LiU ${ }^{1,2,3,4^{*}}$, Wencai Zhu ${ }^{2}$ and Hongfan MA ${ }^{3}$
}

${ }^{1}$ State Key Laboratory of Crystal Material, Shandong University, Jinan 250100, P.R. China

${ }^{2}$ Department of Chemistry, Advance Material Institute of Research, Qilu Normal University, Jinan 250013, P.R. China

${ }^{3}$ Department of Materials, Shandong Jianzhu University, Jinan 250101, P.R. China

${ }^{4}$ Key Laboratory of Colloid and Interface Chemistry, Education Ministry, Shandong University, Jinan 250100, P.R. China

*Corresponding author: Fax: +86 531 66778065; Tel: +86 531 66778065; E-mail: gzliusd@ gmail.com

\begin{abstract}
A theoretical method named as quantitative structure and property relationship (QSPR) was used to investigate corrosion inhibition efficiency of benzimidazole and its derivatives on mild steel in $1 \mathrm{M}$ hydrochloric acid. Some electronic, spatial and thermodynamic properties were selected as descriptors to build relationships between inhibition efficiency and micro-structure information. These descriptors include frontier molecular orbits (LUMO and HOMO), molecular surface area and molecular volume, molecular flexibility, etc. The relationships between descriptors and inhibition efficiency were described by several equations, respectively. Furthermore, an overall equation was built up to describe accurately the relationship between inhibition efficiency and most of the descriptors. These equations were proven to be successful in explaining the corrosion inhibition mechanism of benzimidazole and its derivatives.
\end{abstract}

Key Words: Benzimidazole, Inhibition mechanism, Inhibition efficiency, Quantitative structure and property relationship.

\section{INTRODUCTION}

Corrosion is a real challenge to many chemical industries, as well as a difficult problem to study scientifically ${ }^{1}$. Corrosion can happen in circulating water systems, oil wells, building materials, reaction vessels, pipelines and many other areas where materials such as fuels, lubricants, detergents and metal working fluids are used ${ }^{2,3}$. Corrosion inhibitors have been designed to work in several ways, such as blocking either the cathodic or anodic sites, or scavenging activating ions. These inhibitors must be transported to material surface and adsorbed successfully onto the surface before the inhibition acts effectively. This process involves physisorption and chemisorption. Usually, inhibitors must build up thick layers of coating so that corrosion and oxidation can be prevented. The processes involved are too complicated to model with traditional DFT theory, though DFT methods have been widely used in many areas ${ }^{4-7}$.

Quantitative structure and property relationship has been already applied in corrosion research ${ }^{4,5}$. The best way of using molecular modeling to help the design of new and better corrosion inhibitors is to encapsulate knowledge about how existing inhibitors perform into a structure-property relation and use this to predict the behaviour of new structures. Then the structures with the best predicted property can be investigated in the laboratory.
Popova et al. ${ }^{8}$ investigated the corrosion inhibition of eight diazoles on mild steel in $1 \mathrm{M}$ hydrochloric acid using gravimetric and polarization techniques. They got a good experiment result that inhibition efficiency vary with change of substituents and IE follows as: 5(6)- $\mathrm{NO}_{2}$ - $\mathrm{BIM}<\mathrm{BIM}<2-\mathrm{CH}_{3}-\mathrm{BI}<5(6)-$ $\mathrm{COOH}-\mathrm{BIM}<2-\mathrm{CH}_{2} \mathrm{OH}-\mathrm{BIM}<2-\mathrm{NH}_{2}-\mathrm{BIM}<2-\mathrm{CH}_{2} \mathrm{CN}-$ $\mathrm{BIM}<2-\mathrm{SH}-\mathrm{BIM}$, but no simple correlations were found between the electronic parameters (induction and mesomeric effects of the substituents, ionization potential values) of diazole molecules and their inhibiting properties, neither between molecular area and inhibiting properties.

The present paper focuses on how to build appropriate relationships between macro properties (such as inhibition efficiency, IE) and micro-structure information of these eight diazole inhibitors reported by Popova et al. ${ }^{6}$. To build a good relationship between inhibition efficiency and diazole inhibitors, based on comparing several simple equation, an overall multi-parameter equation was obtained by quantitative structure and property relationship, parameters in this equations were selected from adequate descriptors about micro-structure information (electronic, spatial and thermodynamic properties).

\section{EXPERIMENTAL}

The theoretical foundation of quantitative structure and property relationship is based on the principle of polylinearity. 
According to the theory, a continuous and singular dependence between a property $\mathrm{P}$, which is experimentally measurable and some intrinsic structural factors of molecule $\mathrm{x}_{\mathrm{i}}$, is assumed to be linear in a certain domain of this factor $\mathrm{a}_{\mathrm{i}}$. Under this assumption, the experimental property $\mathrm{P}$ may depend only on one structure factor $\mathrm{x}_{\mathrm{i}}$, so, a regression equation can be found.

$$
\mathrm{P}=\mathrm{a}_{0}+\sum_{\mathrm{i}=1}^{\mathrm{m}} \mathrm{a}_{\mathrm{i}} \mathrm{x}_{\mathrm{i}}
$$

Benzimidazole and its derivatives are selected to carry out the QSPR calculation by using Cerius2 workstation or materials studio (Accelrys Inc., San Diego, CA) ${ }^{7}$ and their structures are shown in Table-1.

STRUCTURAL AND INHIBITION EFFICIENCY OF
BENZIMIDAZOLE AND ITS DERIVATIVES

Molecular structures of eight inhibitors of benzimidazole and its derivatives are optimized by forcite module and the values of descriptors are acquired by using VAMP module. Forcite module is a collection of molecular mechanics tools that can investigate a wide range of systems. The key approximation is that the potential energy surface is represented by a classical forcefield, which are developed by parameterize data from experiment and high level quantum mechanical calculations. VAMP module is a semiempirical molecular orbital package capable of predicting geometries, heats of formation and a host of molecular properties. The forcefield used in this paper is COMPASS (condensed-phase optimized molecular potentials for atomistic simulation studies $)^{8}$, which is the first $a b$ initio forcefield that enables accurate and simultaneous prediction of gas-phase properties (structural, conformational, vibrational, etc.) and condensed-phase properties (equation of state, cohesive energies, etc.) for a broad range of molecules and polymers.

The statistical technique used in our QSPR analysis is genetic function approximation (GFA) approach ${ }^{9}$, which takes inspiration from natural genetics and evolution.

\section{RESULTS AND DISCUSSION}

Some important descriptors, which are possibly correlative with inhibition efficiency, include frontier molecular orbits (LUMO and HOMO), nitrogen atomic charges and ring's charge, molecular surface area and molecular volume, molecular refractivity, molecular flexibility and so on. Table-2 demonstrates the values of these descriptors, which are used to fit and educe the following equations.

HOMO and LUMO eigen values: The following is a simple two-parameter equation including only HOMO and LUMO eigenvalues:

$\mathrm{Y}_{1}=21.10 \times \mathrm{X}_{1}+5.10 \times \mathrm{X}_{2}+256.72, \mathrm{R}^{2}=0.192$ where, $\mathrm{X}_{1}$ and $\mathrm{X}_{2}$ denote HOMO and LUMO eigen value, respectively, $\mathrm{R}^{2}$ represents the square value of the correlative coefficient. Predicted values about inhibition efficiency were calculated according to this equation and listed in Table- 3 as predicted values 1 . By comparing the predicted values with the actual values of inhibition efficiency, it is obvious that the predicted values given by equation (1) have bad accuracy, since only one residual value is less than $5 \%$.

HOMO and LUMO represent highest occupied molecular orbital and lowest unoccupied molecular orbital respectively, the former is associated with the electron donating ability of the molecules and the latter indicate the ability of the molecules to accept electrons. The higher the HOMO eigenvalue, the higher the inhibition efficiency. Fang and $\mathrm{Li}^{10}$ found that there are satisfactory correlations between the quantum chemical parameters and the inhibition efficiency of imidazoline derivatives or amides, respectively. Shokry et al. ${ }^{11}$ got an equation about inhibition efficiency via HOMO energy and LUMO energy, found that high value of HOMO energy and lower value of LUMO would improve efficiency. However, Khalil didn't found HOMO and LUMO energy correlate well with inhibition efficiency of the tested thiosemicarbazide and its derivatives ${ }^{12}$.

Nitrogen atomic charges and ring's total charges: Total charges of six-atom ring and five-atom ring also have great effect on inhibition efficiency of benzimidazole and its derivatives. The relationship between inhibition efficiency and total charges of atoms in the ring is described as the following equation:

$$
\mathrm{Y}_{2}=-123.26 \times \mathrm{X}_{3}+123.30 \times \mathrm{X}_{4}+50.02, \mathrm{R}^{2}=0.337
$$
where, $\mathrm{X}_{3}$ and $\mathrm{X}_{4}$ denote total charges of six-atom ring and five-atom ring, respectively. Predicted values given by equation (2) were listed in Table-3 as predicted values 2 . The eqn. (2) indicated that the total charges of six-atom ring and five-atom ring had different effects on inhibition efficiency. Increase of the total charges of six-atom ring would decrease inhibition efficiency, for five-atom ring the situation is opposite.

The effect of charges of two nitrogen atoms in five-atom ring on inhibition efficiency was studied by eqn. (3) as the following: 


\begin{tabular}{|c|c|c|c|c|c|c|c|c|c|c|}
\hline & & & VALUE & OF DESCRI & $\begin{array}{l}\text { TABLE-2 } \\
\text { IPTORS CALCU }\end{array}$ & JLATED BY QSPR & & & & \\
\hline Structures & $\begin{array}{l}\text { Inhibition } \\
\text { efficiency }^{8}\end{array}$ & & $\log \mathrm{P}$ & $\begin{array}{l}\text { Molecular } \\
\text { refractivity }\end{array}$ & $\begin{array}{l}\text { Molecular } \\
\text { flexibility }\end{array}$ & $\begin{array}{c}\text { Total molecular } \\
\text { mass }\end{array}$ & $\begin{array}{l}\text { Atom } \\
\text { count }\end{array}$ & $\begin{array}{l}\text { Element } \\
\text { count }\end{array}$ & HOMO & LUMO \\
\hline $5(6)-\mathrm{NO}_{2}-\mathrm{BIM}$ & 26.0 & & 2433 & 43.3501 & 1.2981 & 163.136 & 17 & 7 & -9.9117 & -1.9160 \\
\hline BIM & 29.5 & & 2897 & 36.0254 & 0.8026 & 118.139 & 15 & 7 & -8.9792 & 0.1345 \\
\hline $2-\mathrm{CH}_{3}-\mathrm{BIM}$ & 39.0 & & 357 & 38.1169 & 1.0051 & 132.166 & 18 & 8 & -8.8961 & 0.1346 \\
\hline 5(6)-COOH-BIM & 59.0 & & 9881 & 42.7838 & 1.4121 & 162.148 & 18 & 8 & -9.5906 & -0.4722 \\
\hline 2- $\mathrm{CH}_{2} \mathrm{OH}-\mathrm{BIM}$ & 72.0 & & 4801 & 39.8191 & 1.3650 & 148.165 & 19 & 8 & -8.8857 & 0.1044 \\
\hline 2- $\mathrm{NH}_{2}-\mathrm{BIM}$ & 88.0 & & 096 & 40.6398 & 0.9168 & 133.154 & 17 & 7 & -8.5262 & 0.3338 \\
\hline 2- $\mathrm{CH}_{2} \mathrm{CN}-\mathrm{BIM}$ & 90.5 & & 2326 & 43.4403 & 1.5247 & 157.176 & 19 & 9 & -9.1201 & -0.1391 \\
\hline 2-SH-BIM & 98.0 & & 7492 & 44.0473 & 1.1081 & 150.199 & 16 & 7 & -9.1170 & -0.2738 \\
\hline Structures & $\begin{array}{l}\text { Molecular area } \\
\text { (vdW area) }\end{array}$ & $\begin{array}{r}\text { Mo } \\
\text { volun } \\
\text { vo }\end{array}$ & $\begin{array}{l}\text { ecular } \\
\text { ee (vdW } \\
\text { ume) }\end{array}$ & $\begin{array}{c}\text { Total } \\
\text { dipole }\end{array}$ & $\begin{array}{c}\text { Mean } \\
\text { polarizability }\end{array}$ & $\begin{array}{l}\mathrm{N}(\mathrm{H}) \text { : Mülliken } \\
\text { charge }\end{array}$ & $\begin{array}{l}\mathrm{N}(\text { ring) : } \\
\text { Mülliken } \\
\text { charge }\end{array}$ & Ring (6) & Ring (5) & $\begin{array}{l}\text { HOMO- } \\
\text { LUMO }\end{array}$ \\
\hline $5(6)-\mathrm{NO}_{2}-\mathrm{BIM}$ & 164.2838 & & .3672 & 8.649 & 16.3344 & -0.3822 & -0.1710 & -0.5089 & -0.6617 & -7.9957 \\
\hline BIM & 136.3086 & & .5056 & 3.091 & 14.0764 & -0.3884 & -0.1916 & -0.7765 & -0.7141 & -9.1137 \\
\hline 2- $\mathrm{CH}_{3}-\mathrm{BIM}$ & 157.9927 & & .1978 & 3.129 & 15.9956 & -0.3760 & -0.1882 & -0.7714 & -0.5888 & -9.0307 \\
\hline 5(6)-COOH-BIM & 166.4388 & & .0946 & 7.629 & 16.6132 & -0.3844 & -0.1778 & -0.6910 & -0.6853 & -9.1184 \\
\hline 2- $\mathrm{CH}_{2} \mathrm{OH}-\mathrm{BIM}$ & 166.9200 & & .5315 & 2.370 & 16.5738 & -0.3567 & -0.1912 & -0.7651 & -0.5737 & -8.9901 \\
\hline 2-NH$-\mathrm{NIM}$ & 151.2504 & & .3593 & 3.300 & 15.4143 & -0.3973 & -0.2506 & -0.7594 & -0.4804 & -8.8600 \\
\hline 2- $\mathrm{CH}_{2} \mathrm{CN}-\mathrm{BIM}$ & 176.2351 & & .3032 & 0.555 & 17.8315 & -0.3684 & -0.1777 & -0.7567 & -0.5768 & -8.9810 \\
\hline 2-SH-BIM & 158.9427 & 125 & .4962 & 3.095 & 17.1711 & -0.3497 & -0.1349 & -0.7651 & -0.6855 & -8.8432 \\
\hline $\begin{array}{l}\text { (Ring (5) and Rin } \\
\text { respectively) }\end{array}$ & 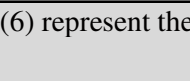 & & & he six-ator & . & lo $\mathrm{N}(\mathrm{H})$ and & & & & \\
\hline & ALL DATA ABC & UT AC & TUAL V & ILUES, PREI & $\begin{array}{l}\text { TABLE-3 } \\
\text { EDICTED VALUI }\end{array}$ & JES AND RESIDUA & AL VALU & ES FOR IE $(\%$ & $(\%)$ & \\
\hline Actual values for IE & Predicted va & ues 1 & Residua & values 1 & Predicted values 2 & Residual values & Predi & cted values 3 & Reside & al values3 \\
\hline 26.0 & 37.7843 & & -11.7 & 4387 & 31.160917 & -5.160917 & & 3.652245 & -17 & 652245 \\
\hline 29.5 & 67.9165 & & -38.4 & 6569 & 57.683370 & -28.183370 & & .536888 & -16 & 036888 \\
\hline 39.0 & 69.6715 & & -30.6 & 1529 & 72.503950 & -33.503950 & & 3.387993 & -24 & 387993 \\
\hline 59.0 & 51.9204 & & $7.0^{\circ}$ & 9523 & 50.695971 & 8.304029 & & 4.029470 & & 70530 \\
\hline 72.0 & 69.7371 & & 2.26 & 2885 & 73.589231 & -1.589231 & & 5.915097 & -23 & 915097 \\
\hline 88.0 & 78.4934 & & 9.5 & 6595 & 84.390336 & 3.609664 & & 5.074728 & & 25272 \\
\hline 90.5 & 63.5487 & & 26.9 & 1239 & 72.171660 & 18.32834 & & .515236 & & 84764 \\
\hline 98.0 & 62.9277 & & 35.0 & 2244 & 59.804564 & 38.195436 & & 4.888343 & & 11657 \\
\hline Actual values of $\mathrm{IE}^{8}$ & Predicted va & ues 4 & Residua & values 4 & Predicted values 5 & Residual values & Predi & cted values 6 & Residu & la values 6 \\
\hline 26.0 & 74.8982 & & -48.8 & 8203 & 58.892619 & -32.892600 & & 5.038000 & & 38000 \\
\hline 29.5 & 38.7257 & & -9.2 & 5718 & 28.689012 & 0.810988 & & 9.967000 & & 67000 \\
\hline 39.0 & 47.9643 & & -8.9 & 4354 & 75.082538 & -36.082500 & & 9.000000 & & 00000 \\
\hline 59.0 & 69.3785 & & -10.3 & 8538 & 49.885618 & 9.114382 & & 3.546000 & & 54000 \\
\hline 72.0 & 51.9925 & & 20.0 & 7451 & 75.557410 & -3.557410 & & 1.143000 & & 57000 \\
\hline 88.0 & 65.0544 & & 22.9 & 5517 & 68.920253 & 19.079750 & & 7.920000 & & 80000 \\
\hline 90.5 & 71.4013 & & 19.0 & 8654 & 75.083875 & 15.416130 & & 1.648000 & & 48000 \\
\hline 98.0 & 82.5848 & & 15.4 & 5191 & 69.888675 & 28.111330 & & 7.738000 & & 62000 \\
\hline
\end{tabular}

$\mathrm{Y}_{3}=1596.44 \times \mathrm{X}_{5}-571.97 \times \mathrm{X}_{6}+556.01 \mathrm{R}^{2}=0.400$ where, $X_{5}$ and $X_{6}$ denote the Mülliken charges of $N(H)$ and $\mathrm{N}($ ring), respectively. Predicted values were listed in Table-3 as predicted values 3 . The coefficient of $\mathrm{X}_{5}$ was three times bigger than that of $\mathrm{X}_{6}, \mathrm{X}_{5}$ had a positive effect on the inhibition efficiency, but $\mathrm{X}_{6}$ had a negative effect.

Only two of absolute values of the residual values given by eqn. (2) were less than $5 \%$ and no absolute value of the residual values given by eqn. (3) was less than $5 \%$, so, neither eqn. (2) nor eqn. (3) has good accuracy.

It is concluded from the eqns. (2) and (3) that nitrogen atomic charges and ring's charges have an important effect on inhibition efficiency, which is according to Shokry et al. ${ }^{11}$ i.e., good inhibitors not only could be synthesized conveniently, but also contain electron cloud on the aromatic ring or the electronegative atoms such as nitrogen and oxygen.
Molecular refractivity and flexibility: The effect of molecular refractivity and flexibility on inhibition efficiency was described by the following equation:

$$
\mathrm{Y}_{4}=6.15 \times \mathrm{X}_{7}-17.89 \times \mathrm{X}_{8}-168.42 \quad \mathrm{R}^{2}=0.273
$$
where, $X_{7}$ and $X_{8}$ denote molecular refractivity and molecular flexibility, respectively. Predicted values were listed in Table-3 as predicted values 4 . The coefficient of $X_{8}$ was three times more than that of $X_{7}, X_{8}$ had a positive effect on inhibition efficiency, while had a negative effect. Only two of absolute values of the residual values given by eqn. (4) were less than $10 \%$ and no one was less $5 \%$.

Molecular area and volume: The effect of molecular area and volume was described by the following equation:

$\mathrm{Y}_{5}=11.95 \times \mathrm{X}_{9}-12.74 \times \mathrm{X}_{10}-230.123, \mathrm{R}^{2}=0.329$ (5) where, $X_{9}$ and $X_{10}$ denote molecular area (vdW area) and molecular volume (vdW volume), respectively. The molecular 
surface area and volume determines the extent to which a molecule exposes itself to the external environment. These two descriptors are related to binding, transportation and solubility. Increasing molecular area can help to get greater inhibition efficiency. Only three of absolute values of residual values given by eqn. (5) were less than $10 \%$ and two were less than $5 \%$.

A certain tendency of IE increase with molecular area increase can be followed according to eqn. (5), but the effects of molecular area and volume are slightly pronounced ${ }^{6,13}$.

Total impact and a multi-parameter equation: It was necessary to make an overall multi-parameter equation, because these simple equations without good accuracy can only explain how single or a few descriptors affect simply the inhibition efficiency. The multi-parameter equation with six-variables was shown as the following:

$$
\begin{aligned}
& Y=10.80 \times X_{1}+43.03 \times X_{2}+103.84+X_{3}-4.73 \times \\
& X_{4}-225.43 \times X_{5}-240.54 \times X_{6}+324.28, R^{2}=0.999
\end{aligned}
$$
where, $\mathrm{X}_{1}, \mathrm{X}_{2}, \mathrm{X}_{3}, \mathrm{X}_{4}, \mathrm{X}_{5}$ and $\mathrm{X}_{6}$ denote molecular refractivity, molecular flexibility, HOMO eigenvalue, LUMO eigen value, Mülliken charge of N(ring) and ring(5) charge, respectively. Predicted values were listed in Table- 3 as predicted values 6 . $R^{2}$, the square value of the correlative coefficient of equ. (6), was as high as 0.999 . The absolute values of all the residual values were less than $2 \%$, obviously this overall equation has a very high accuracy. Using the data from the first and last two columns in Table-3, Figs. 1 and 2 were drawn to investigate how good the accuracy is. It is clear that the difference between actual values and predicted values given by eqn. (6) is quite small, their curves are perfectly overlapped.

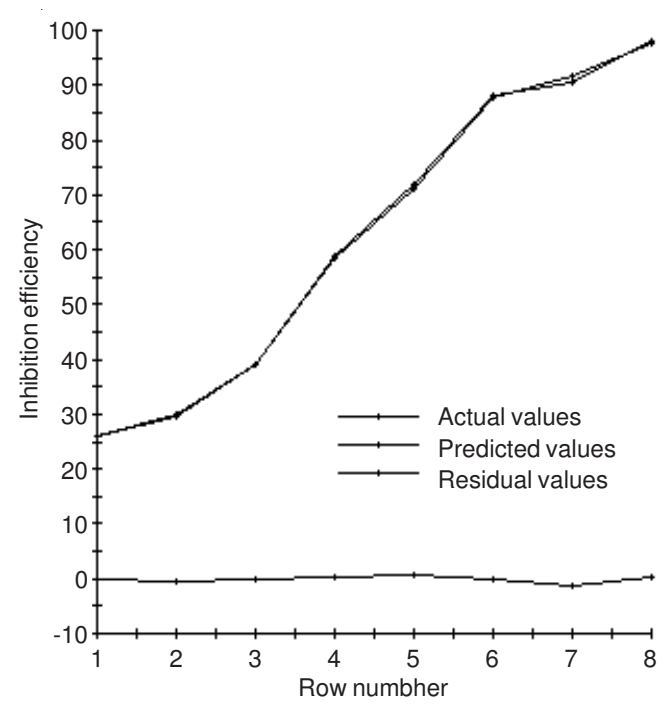

Fig. 1. GFA plot of actual values, predicted values and residual values

Both molecular refractivity and molecular flexibility have opposite effects on inhibition efficiency. The values of N(ring) and ring (5) had similar effects. The HOMO eigen value and LUMO eigen value also have opposite effects and the effect of the former was much higher than that of the latter.

\section{Conclusion}

Quantitative structure and property relationship was used to investigate corrosion inhibition mechanism of benzimidazole

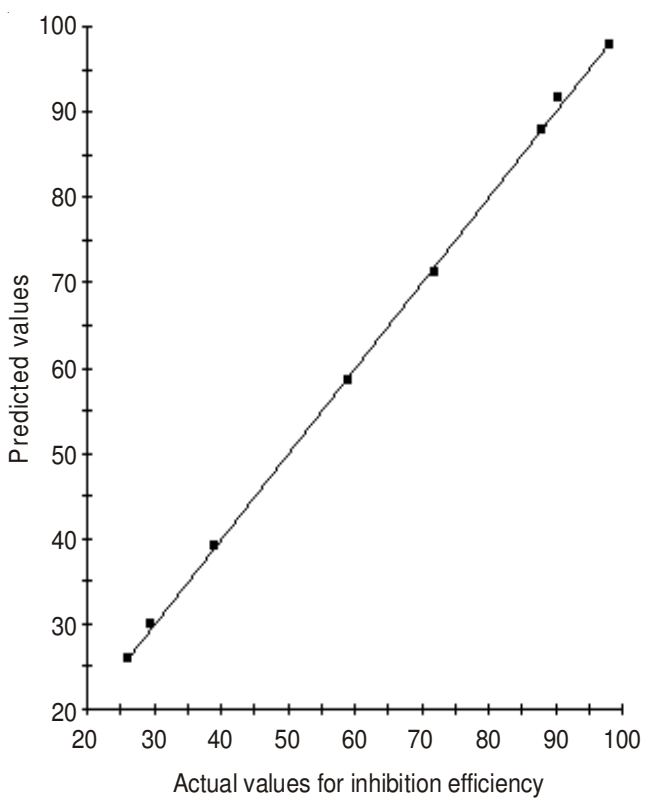

Fig. 2. Disperse pot of actual values and predicted values

and its derivatives on mild steel in $1 \mathrm{M}$ hydrochloric acid. Some electronic, spatial and thermodynamic properties were selected as descriptors to build a relationship between the macro-property (such as IE) and the micro-structure. Several simple equations and a multi-parameter equation were obtained, the former could explain how single or a few descriptors affect simply the inhibition efficiency and the latter have good accuracy and could explain how all of the descriptors affect inhibition efficiency.

\section{ACKNOWLEDGEMENTS}

This work is supported by the Outstanding Middle-Aged Scientists Foundation of Shandong Province of China (No. 2008BS04031).

\section{REFERENCES}

1. Y. Bao, C.X. Zhang, W.B. Yang, J.T. Hu and X.M. Sun, Sci. Total Environ., 419, 144 (2012).

2. W.N. Yu, J.T. Hu, F. Xu, X.Y. Sun, R. Gao, Q.Z. Zhang and W.X. Wang, Environ. Sci. Technol., 45, 1917 (2011).

3. F. Xu, W.N. Yu, Q. Zhou, R. Gao, X.Y. Sun, Q.Z. Zhang and W.X. Wang, Environ. Sci. Technol., 45, 643 (2011).

4. C.X. Zhang, T.L. Sun and X.M. Sun, Environ. Sci. Technol., 45, 4756 (2011).

5. K.F. Khaled, K. Babic-Samardzija and N. Hackerman, Electrochim. Acta, 50, 2515 (2005).

6. A. Popova, M. Christov, S. Raicheva and E. Sokolova, Corros. Sci., 46, 1333 (2004).

7. CERIUS2, version 4.6; Molecular Simulations Inc.: San Diego, CA, (2002).

8. H. Sun, J. Phys. Chem. B, 102, 7338 (1998).

9. D. Rogers and A.J. Hopfinger, J. Chem. Inf. Comput. Sci., 34, 854 (1994).

10. J. Fang and J. Li, J. Mol. Struct. (Theochem.), 593, 179 (2002).

11. H. Shokry, M. Yuasa, I. Sekine, R.M. Isaa, H.Y. El-Baradie and G.K. Gomma, Corros. Sci., 40, 2173 (1998).

12. N. Khalil, Electrochim. Acta, 48, 2635 (2003).

13. A. Popova, M. Christov and T. Deligeorgiev, Corrosion, 59, 756 (2003). 